\title{
European Society of Cardiology (ESC) Congress Report From Munich 2012
}

\author{
Yukio Ozaki, MD, PhD
}

\begin{abstract}
The Annual Congress of the European Society of Cardiology (ESC) was held in Munich from the $26^{\text {th }}$ to $29^{\text {th }}$ of August 2012. The daily attendance ranged from 26,600 to 27,407 up to the $28^{\text {th }}$ and several important issues were presented and discussed, including antiplatelet therapy for acute coronary syndrome (TRILOGY ACS), transcatheter aortic valve implantation, renal denervation, novel oral anticoagulants for atrial fibrillation (AFib), AFib ablation, the impact of the Great East Japan Earthquake on cardiovascular disease, management of vasospastic angina, plaque rupture and erosion (ESC-JCS [Japanese Circulation Society] joint session), heart failure, and FFR-guided percutaneous coronary intervention outcome. Three ESC "GOLD MEDALS" were awarded, including one to Professor Ryozo Nagai, the first Asian to receive this award. The ESC meeting has become one of the most important for updating not only general cardiologists' education but also specialists' expertise. Japan topped the number of abstracts submitted to ESC 2012 (>1,200 abstracts), while the ESC would like to establish a strong collaboration with the Japanese Cardiology Society. Relations between ESC and JCS will become closer and more favorable year by year. (Circ $J$ 2012; 76: 2530-2535)
\end{abstract}

Key Words: Arrhythmia; Coronary artery disease; East Japan Great Earthquake; European Society of Cardiology (ESC); Heart failure

\section{Opening Ceremony}

The European Society of Cardiology (ESC) Annual Congress was held in Munich from Saturday $25^{\text {th }}$ to Wednesday $30^{\text {th }}$, August 2012. At the opening ceremony, President Miichel Komajda awarded ESC gold medals to Professor Patrick Serruys (the Netherlands), Professor Pedro Brugada (Belgium) and Professor Ryozo Nagai (Japan).

I would like to seriously congratulate Professor Ryozo Nagai for his gold medal, because he is the first Asian (and the first Japanese) to obtain this award, together with the world-famous interventional cardiologist, Professor Patrick Serruys, and arrhythmia specialist, Professor Pedro Brugada. I would like to briefly introduce these 3 great cardiologists (Figure 1).

\section{Professor Ryozo Nagai (Japan)}

Professor Ryozo Nagai is a distinguished Japanese researcher, Chairman of Department and President of the University Hospital. He has significantly contributed to basic science by disclosing the presence of 3 types of smooth muscle myosin isoforms, and has also revealed that the transcription factor KLF5 is responsible for regulating their transformation. ${ }^{1,2}$

Professor Nagai combines basic research with clinical medicine. In his introduction video at the ESC ceremony, he stated that he can only really find the research theme derived from

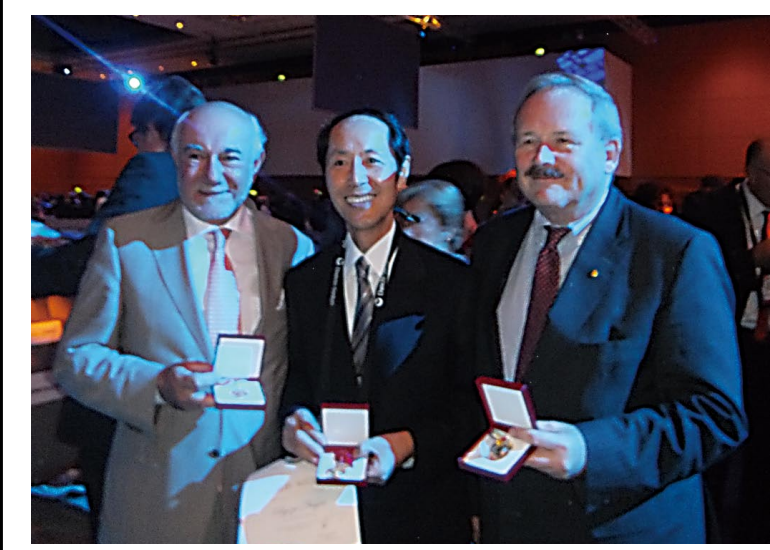

Figure 1. European Society of Cardiology (ESC) "GOLD MEDALISTS", 2012. (L-R) Professor Pedro Brugada (Belgium), Professor Ryozo Nagai (Japan) and Professor Patrick Serruys (the Netherlands).

inquiries in daily clinical practices. Subsequently, Professor Nagai became the cardiologist to advise Emperor Akihito to undergo coronary artery bypass grafting (CABG). ${ }^{3}$

The opinions expressed in this article are not necessarily those of the editors or of the Japanese Circulation Society.

Released online October 18, 2012

Director, Department of Cardiology, Fujita Health University Hospital, Toyoake, Japan

Mailing address: Yukio Ozaki, MD, PhD (Netherlands), FACC, FESC, Professor of Cardiology, Director, Department of Cardiology,

Fujita Health University Hospital, 1-98 Dengaku, Kutsukake, Toyoake 470-1192, Japan. E-mail: ozakiyuk@ fujita-hu.ac.jp

ISSN-1346-9843 doi:10.1253/circj.CJ-66-0051

All rights are reserved to the Japanese Circulation Society. For permissions, please e-mail: cj@j-circ.or.jp 


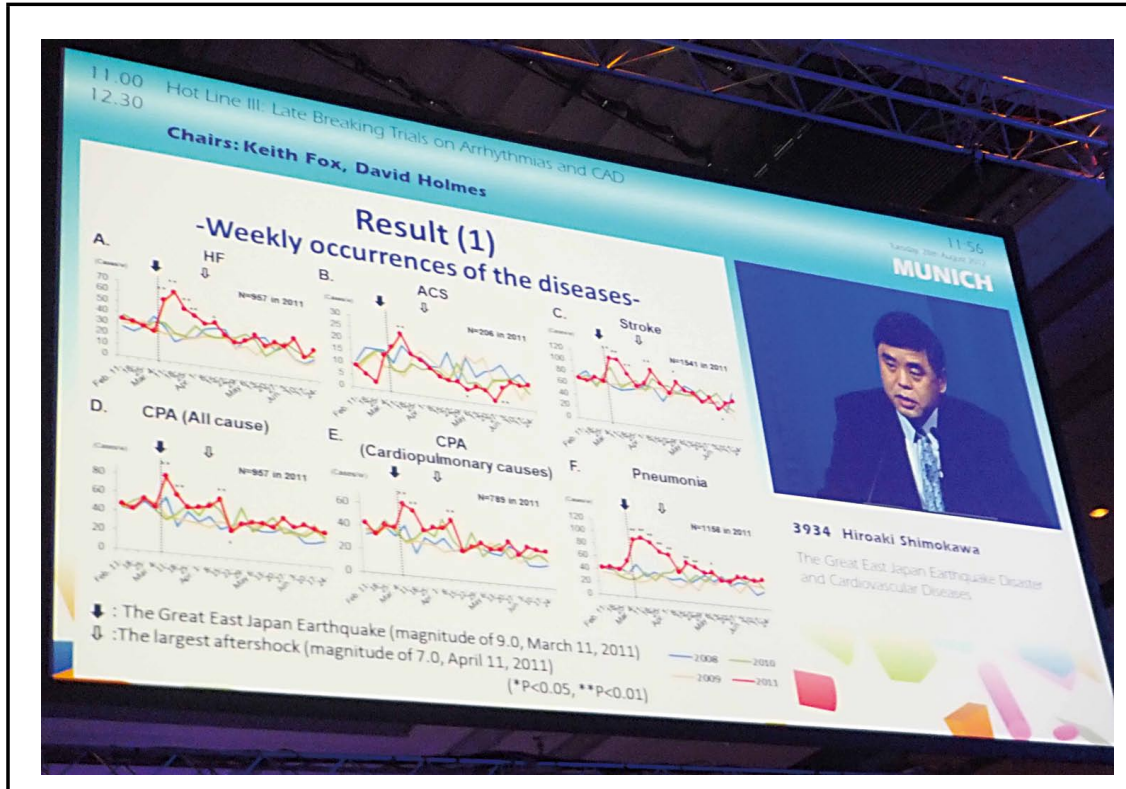

Figure 2. Professor Hiroaki Shimokawa showing the sharp rise in the incidence of cardiovascular disease following the Great East Japan Earthquake in March 2011, during the "Hot Line Session" at the Annual Congress of the European Society of Cardiology 2012.

\section{Professor Patrick Serruys (The Netherlands)}

Professor Patrick Serruys gave the Andreas Grüntzig lecture on interventional cardiology at ESC 2000 in Amsterdam, where he predicted that the drug-eluting stent (DES) would bring a bright future for interventional cardiology (ie, the $3^{\text {rd }}$ revolution in percutaneous coronary intervention (PCI), mainly delivered by Professor Patrick Serruys and his colleagues). ${ }^{4}$ The 1 st revolution was the balloon angioplasty performed by Andreas Grüntzig and his coworkers, subsequently reported in $1979.5^{5}$ Although the $2^{\text {nd }}$ revolution of coronary bare-metal stent (BMS) implantation was first initiated at Toulouse, Lausanne and Rotterdam in 1986, serious complications were recorded because of the lack of strict antiplatelet therapy and subsequently stent implantation temporarily ceased. BMS had to await wide spread use in daily clinical practices until the establishment of the usefulness of bailout management of coronary dissection initially based on Rotterdam experience, ${ }^{6}$ as well as after the demonstration of significant reduction of restenosis as compared to balloon angioplasty by Professor Patrick Serruys and his colleagues (BENESTENT study). ${ }^{7}$ The $4^{\text {th }}$ revolution is the "biodegradable scaffold" introduced by his group as well. ${ }^{8}$ In the ESC opening ceremony, Professor Serruys said that "he is working very hard" and that "It takes five to ten years of intense effort to establish novel technology". Although Professor Serruys was involved in 3 of the 4 major revolutions in the field of coronary intervention, he finally became a "GOLD MEDALIST" for his longtime contribution to the field of PCI. ${ }^{3}$

\section{Professor Pedro Brugada (Belgium)}

In 1987, while he was examining a 3-year-old boy who was having multiple episodes of syncope, Professor Pedro Brugada found that the boy had an unusual ECG showing ST-segment elevation limited to leads $\mathrm{V}_{1-3}$. After seeing similar 7 patients, Professor Brugada published all 8 cases together with new concept. ${ }^{9}$ With his brothers, Professor Brugada was able to define the genetic basis of the condition as a mutation in the sodium channel gene SNC5A. Professor Brugada still spends around $60 \%$ of his working week seeing patients with Brugada syndrome, especially those arriving from all over the world for a second opinion. ${ }^{3}$

\section{Hot Line Session: TRILOGY ACS}

\section{Similar Results Obtained from Prasugrel vs. Clopidogrel Arms: Initial Results in Medically Managed Acute Coronary Syndrome (ACS)}

Professor Magnus Ohman presented the results of the Targeted Platelet Inhibition to Clarify the Optimal Strategy to Medically Manage Acute Coronary Syndromes (TRILOGY ACS), which were simultaneously published in the New England Journal of Medicine. ${ }^{10}$ From June 2008 to September 2011, 7,243 patients were randomized to prasugrel (10 mg daily) or clopidogrel ( $75 \mathrm{mg}$ daily). The study was performed at 966 sites in 52 countries with a follow-up of 17 months. The primary endpoint comprised a composite of death from cardiovascular causes, myocardial infarction (MI) or stroke, and events occurred in $13.9 \%$ of the prasugrel group compared with $16 \%$ with clopidogrel [hazard ratio (HR) $0.91 ; 95 \%$ confidence interval (CI) $0.79-1.05 ; \mathrm{P}=0.21$ ]. No significant difference was found in ACS patients treated with prasugrel or clopidogrel without PCI. ${ }^{10}$

\section{New ESC 2012 AFib Guideline}

\section{Novel Oral Anticoagulants (OACs) for Atrial Fibrillation (AFib)}

Professor P.E. Vardas, ESC President 2012-2014, stated that the efficacy of stroke prevention with aspirin is weak, with a potential for harm because its risk of major bleeding is not different from that of OACs, especially in the elderly. ${ }^{11}$ The novel OACs, on the other hand, offer efficacy, safety and convenience when compared with conventional oral anticoagulation. ${ }^{11}$ If an OAC is recommended, one of the novel drugs should be considered instead of conventional OACs for most patients with nonvalvular AFib (Class IIa A). Another most important addition to pharmacological cardioversion of AFib is vernakalant, a new intravenous antiarrhythmic agent. Furthermore, the current guideline upgrades to Class I A recommendation of catheter ablation for symptomatic paroxysmal 


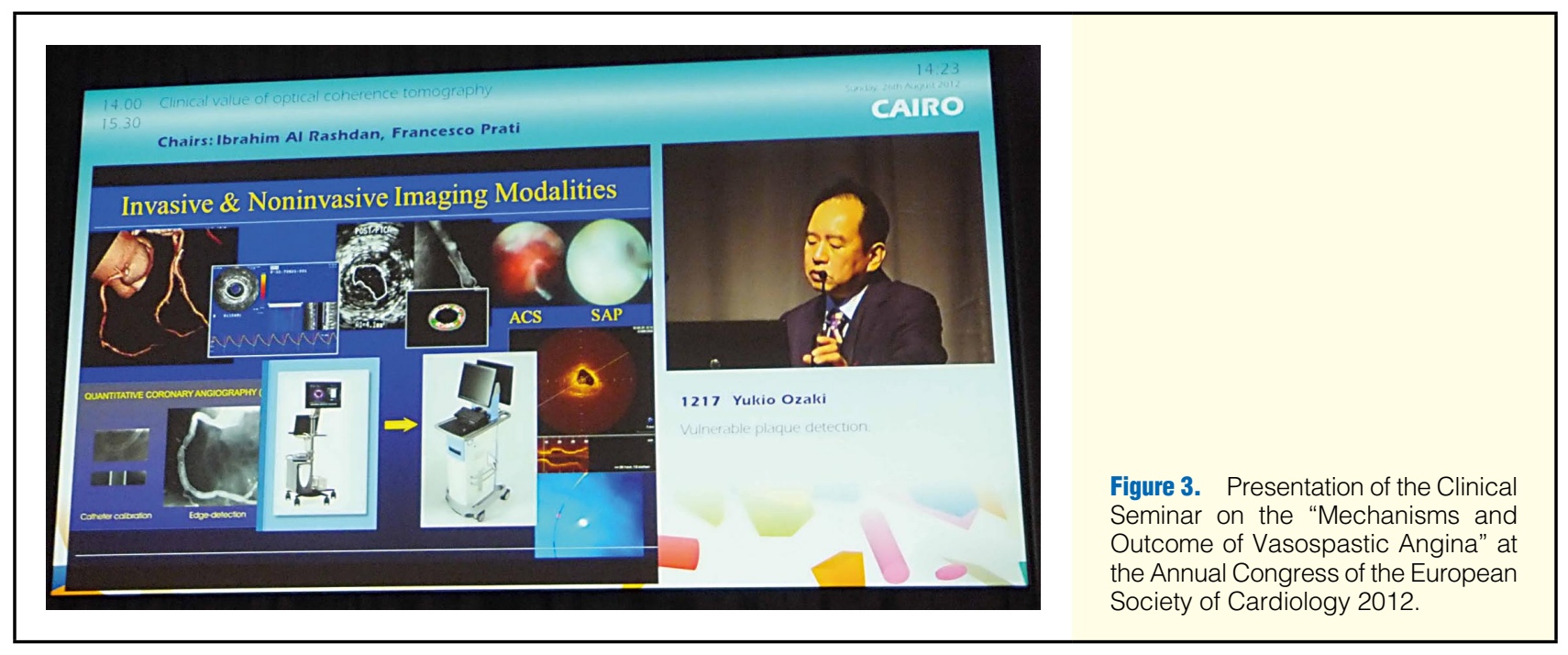

AFib in patients who have previously failed a trial of antiarrhythmic medication. The new ESC guideline for AFib 2012 should contribute to favorable clinical outcomes for patients with paroxysmal AFib. ${ }^{11}$

\section{ESC Pilot Registry for AFib Ablation}

Dr Elena Arbelo from Hospital Clinic de Barcelona, Spain reported the first-year results of the ESC pilot registry for AFib ablation. A total of 1,410 patients from 72 centers in 10 European countries were enrolled in the registry. ${ }^{3}$ The centers selected were doing medium to high volumes, with a minimum of 50 ablations per year. The median age of the patients was 60 years, with one-third of the population being women. The procedure was considered to be successful in $74 \%$ of patients, without documentation of arrhythmias after a 3-month period; however, $32 \%$ of patients were still taking antiarrhythmic drugs. Although complications during the first year after ablation were infrequent $(2.6 \%)$, including cerebrovascular events $(0.54 \%)$ and vascular injuries $(0.71 \%)$, the overall perioperative complication rate was $7.7 \%$ and $1.7 \%$ of these were major. ${ }^{3}$ Dr Elena Arbelo stated that "if the patient's main reason to undergo ablation is to get rid of medication, this might be difficult in one-third of the patients".

\section{Hot Line Session: The Great East Japan Earthquake and Spike in the Incidence of CVD}

Professor Hiroaki Shimokawa demonstrated that the Great East Japan Earthquake was associated with a spike in the incidence of cardiovascular disease (CVD) (Figure 2), and his paper was simultaneously published in the European Heart Journal. ${ }^{12}$

The Great East Japan Earthquake and Tsunami on $11^{\text {th }}$ March 2011 killed nearly 16,000 people and was associated with a sharp rise in the incidence of CVD. Professor Shimokawa and colleagues investigated all 124,152 ambulance transport records in the Miyagi prefecture dating from 11 February to 30 June for each year from 2008 to 2011 . They reported that the weekly occurrence of all CVDs was significantly higher after the earthquake than in the preceding 3 years. The occurrence of ACS and of cardiopulmonary arrest (CPA) showed a rapid increase, followed by a sharp decline, whereas that of heart failure (HF) and pneumonia showed a prolonged increase for more than 6 weeks. The incidence of stroke and
CPA showed a second peak after the largest aftershock, which occurred in April. Blood pressure was also significantly elevated after the earthquake. Professor Shimokawa noted that discontinuation of drugs, activated sympathetic nervous system, rising blood pressure, and the increased occurrence of tachyarrhythmia and infections were all involved in the increased occurrence of cardiovascular events after the Great Earthquake of Japan. At the end of his presentation there was wild applause.

\section{Bench-to-Bedside Session: The Story of the Inventor of the TAVI}

Dr Henning Rud Andersen was the inventor of transcatheter aortic valve implantation (TAVI) and Dr Alan Cribier performed the first in-human TAVI 10 years ago. While Dr Andersen was a cardiologist at Aarhus University Hospital, Denmark, he attended an interventional meeting in February 1989 in the USA, where he was in the audience listening to Julio Palmaz's experience of using coronary stents in dogs. He suddenly thought that it could be useful to make a larger stent and place it inside the aortic valve. ${ }^{3}$ This was the starting point of TAVI. Although Dr Andersen licensed the patent to a small American company, it was later sold out to Edwards Lifesciences. ${ }^{3}$ Currently, TAVI procedures have been performed in approximately 50,000 patients, with the longest patient experience being nearly 7 years. At the end of the session, Chairman Professor Patrick Serruys, suggested that new technology would play a role in the further development of TAVI.

\section{Hot Line Session: TAVI Accounts for Almost 25\% of German Aortic Valve Registry}

Professor Friedrich Mohr, who is well known as a co-Chairman of the SYNTAX study, presented data from the German TAVI registry. ${ }^{3}$ The current analysis was of the outcomes in 13,860 enrolled patients. Of them, 6,523 had surgical aortic valve replacement (AVR) without CABG, 3,462 had surgical AVR with CABG, 2,694 had transvascular TAVI and 1,181 had transapical TAVI. The results show that in-hospital mortality was $2.1 \%$ for patients having AVR without CABG, $4.5 \%$ for AVR with CABG, $5.1 \%$ for transvascular TAVI and $7.7 \%$ for transapical TAVI. 
There appears to be a deterioration in the TAVI groups in terms of mortality, but the mean age of the patients who underwent AVR was 68.3 years, whereas that of the TAVI patients (transvascular and transapical) was 81.0 and 80.3 years, respectively. ${ }^{3}$ Professor Friedrich Mohr said there is now a tendency applying TAVI for younger and low-risk patients.

\section{Clinical Seminar: Mechanisms and Outcome of Vasospastic Angina Organized by the Chairpersons, Professors Hisao Ogawa and Attilio Maseri}

The learning object of this session was to provide new information on the mechanisms, diagnosis and treatment of coronary spasm, a frequently neglected but important mechanism of cardiovascular disease (Figure 3). Indeed, coronary spasm plays a key role in vasospastic angina and an important role in ACS. Furthermore, it is not rare "refractory to current therapeutic approaches". 3

First, Dr Shimokawa presented the pathogenetic mechanism of coronary spasm, including inflammation and the importance of Rho-kinase, ${ }^{13}$ and he also referred to coronary artery spasm treated with DES. Second, Dr Sechtem addressed the diagnostic challenges, including acetylcholine testing, and emphasized the importance of coronary spasm in ACS in Caucasian patients. Third, Dr Ozaki presented the therapeutic challenges and highlighted the higher frequency of this syndrome in Asians than in Caucasians, the effectiveness of calcium-channel blockers and statins, the variability in the location of the spasm, and the limitations of PCI. Finally, Dr Kaski explained the long-term prognosis and also presented that acute MI (AMI) and sudden death occurred in 10-20\% of patients with coronary spasm, and the indications of implanted cardiac defibrillators. All the presenters received many inquiries from the large audience even after the session.

Professor Ogawa closed the seminar with the following words "This clinical seminar was very important in the point that coronary spasm was discussed in the European Cardiac Society".

\section{Hot Line Session: Target for STEMI Prevention Focus on Younger Women: Data Derived From French Registry Study}

Data from French registries of ST-segment elevation MI (STEMI) patients covering more than 15 years show that the mortality rate decreased by a remarkable $68 \%$. The analysis presented in the Hot Line session was also published online by the Journal of the American Medical Association. ${ }^{14}$

Dr Nicolas Danchin presented that the 30-day mortality rate declined from $13.7 \%$ to $4.4 \%$ in STEMI patients, while thier age decreased progressively from 66 to 63 years old. ${ }^{14}$ This decreased mortality was generally explained by progress in reperfusion therapy. Dr Danchin concluded that "young women are at an increasing risk of developing AMI and there is a very strong link here with smoking and to a lesser extent with obesity".

\section{New ESC 2012 AMI-STEMI Guidelines}

New ESC guidelines for the management of AMI in patients with STEMI were presented during the congress and the following crucial points should be highlighted. ${ }^{15}$

- First medical contact (FMC) to ECG: $\leq 10 \mathrm{~min}$

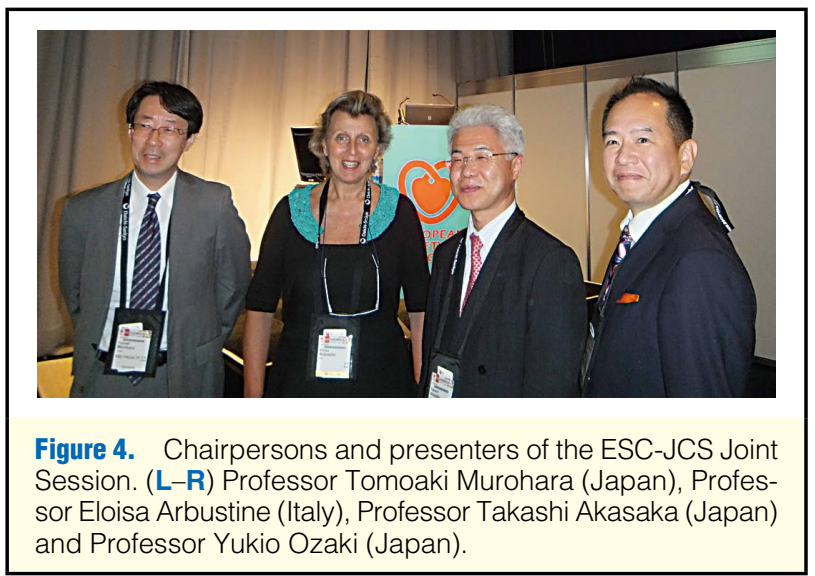

- FMC to reperfusion:

(1) Primary PCI: $\leq 90 \mathrm{~min}$ ( $\leq 60 \mathrm{~min}$ if patient presents within $2 \mathrm{~h}$ of onset, with large area at risk, or directly to PCI-capable hospital)

(2) Fibrinolysis : $\leq 30 \mathrm{~min}$

(3) Acceptable delay for primary PCI rather than fibrinolysis: $\leq 120 \mathrm{~min}$

(4) Stenting is recommended for primary PCI, limited to the culprit vessel with the exception of cardiogenic shock and persistent ischemia.

(5) Routine thrombus aspiration should be considered, but not distal protection devices.

\section{ESC-JCS Joint Session: Assessment of Coronary Plaque Rupture and Erosion by Invasive and Noninvasive Means, Organized by 2 Chairpersons, Professors Toyoaki Murohara and Eloisa Arbustine}

Atherosclerotic plaques associated with ACS on histopathological characterisation demonstrate either a ruptured fibrous cap or an intact fibrous cap. The latter lesions are often referred to as plaque erosions and are responsible for up to onethird of culprit lesions in ACS patients.

First, Professor Renu Virmani described the different pathological aspects of plaque rupture and erosion. Second, Professor Pim de Feyter described the limitations to differentiating coronary plaque rupture and erosion and third, Professor Yukio Ozaki presented the added value of invasive imaging, especially for plaque erosion. ${ }^{16}$ Finally, Professor Takashi Akasaka showed the clinical relevance of invasive imaging.

Professor Murohara concluded this session (Figure 4) with the following comment; "while each clinical imaging modality has its strengths and weaknesses, the combination of invasive and noninvasive imaging modalities, as well as pathology, could contribute to understanding the underlying mechanisms of plaque vulnerability in humans and subsequently to offering better treatments for the patients with ACS".

\section{Hot Line Session: FFR Guided PCI vs. Medical Therapy Alone in Stable CAD (FAME 2)}

Dr De Bruyne led the discussion on whether fractional flow reserve (FFR)-guided therapy has improved outcomes for patients with stable CAD in 28 centers in Europe and North America (FAME 2 trial), which was immediately published in the New England Journal of Medicine. ${ }^{17}$ The FAME 2 trial 


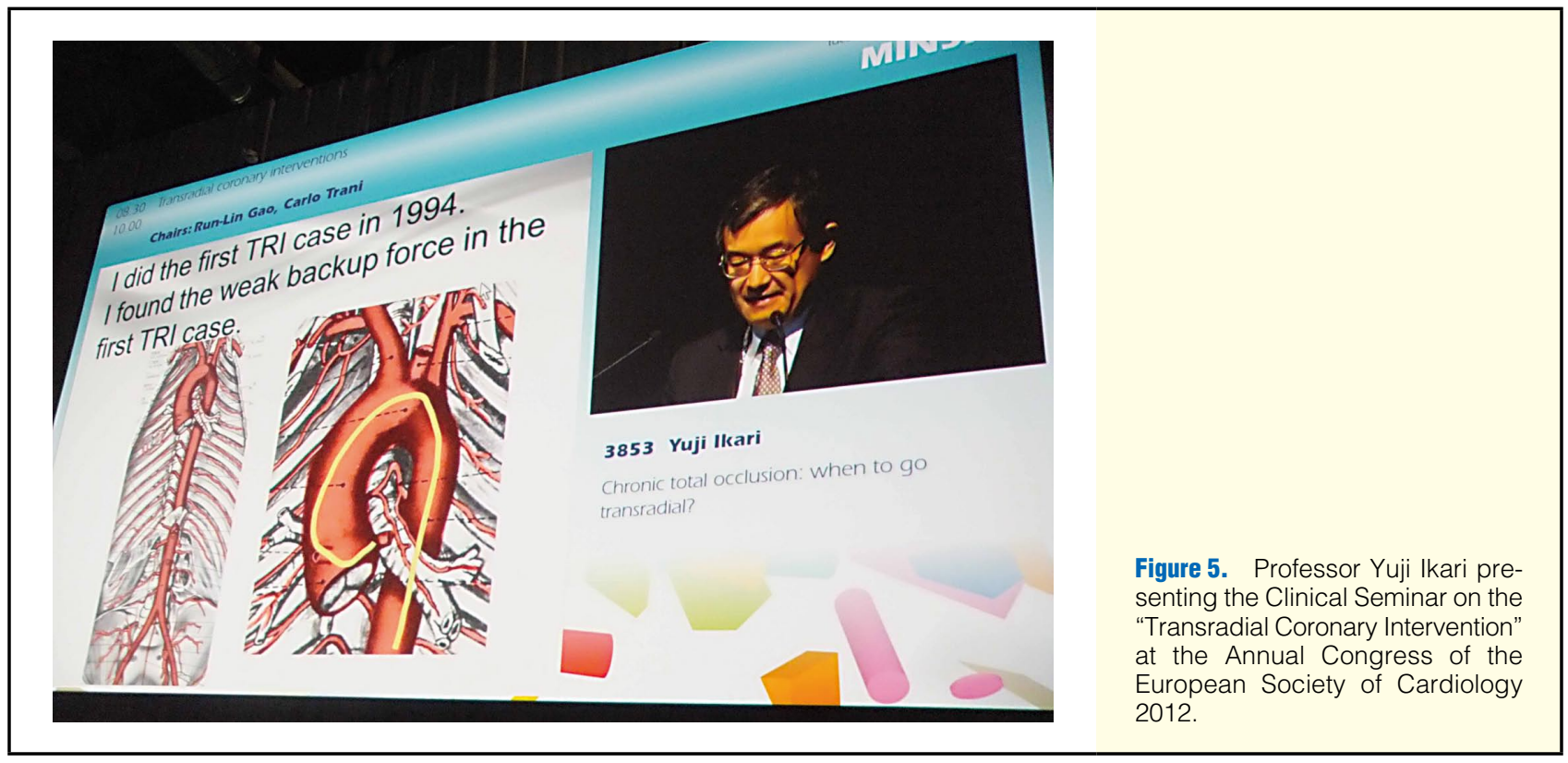

compared clinical outcomes for FFR-guided PCI plus medical therapy with medical therapy alone in patients with stable CAD; 1,220 patients found to have at least 1 functionally significant stenosis (FFR $<0.80)$ were randomly assigned to one of the 2 arms. Dr De Bruyne indicated that the rate of urgent revascularization in the PCI group was significantly lower than that in the medical-therapy group $(0.7 \%$ vs. $9.5 \%$, $\mathrm{P}<0.001) .{ }^{17}$ The importance of the presence of ischemia to performing PCI was reconfirmed by this study.

\section{Clinical Seminar: TRI}

Transradial coronary intervention (TRI) has been widely used in various clinical settings, including simple lesions, complex lesions, post-CABG lesions, ACS lesions and CTO. The recent ESC Guideline for AMI referred to primary PCI being preferably performed by the radial approach. Professor Yuji Ikari (Figure 5) presented the long history of the development of suitable catheters for TRI, as well as the possibility of applying this technique to the recent retrograde approach for CTO ${ }^{18}$ Professor Ikari was showered with praise at the end of his presentation.

\section{ESC Press Briefing: Novel Approaches to Treating HF}

New approaches to the treatment of HF, including gene therapy, autonomic nerve stimulation and percutaneous devices, were presented in a press briefing.

Dr Roger Hajjar explained that SERCA2a is a critical transporter that facilitates the uptake of calcium into the sarcoplasmic reticulum, and that gene therapy would contribute to the reduction in cardiac deaths, especially under the condition of ventricular assist device usage. ${ }^{3}$ We anticipate a new revolution in the management of chronic and severe HF.

\section{ESC Press Briefing: Recent Progress in Renal Denervation}

Renal denervation could be a new therapeutic application for the patients with hypertension and some types of HF. The origin of the denervation concept came from observations that renal nerves are overactive in the setting of hypertension. Many bioengineering companies are now developing new ways to destroy the nerves, such as cryogenic catheters to freeze them, neurotoxic drugs to inject into them, and noninvasive external ultrasound beams. ${ }^{3}$

Recently, Taborsky, from Palacky University, Czech Republic, randomized patients to receive either renal denervation and standard therapy $(n=26)$ or standard therapy alone $(n=25)$. At 12 months, 8 patients in the denervation group were rehospitalized for HF compared with 18 in the standard therapy group $(\mathrm{P}<0.001)$. Darren Mylotte from the Cardiovascular Institute, Paris-Sud, France, also presented a real-world study of renal denervation in 35 consecutive patients. Successful bilateral sympathetic denervation was achieved in 33 patients with no major procedural complications. ${ }^{3}$

Although renal denervation appears to show promise for the future, the technological revolution should occur to the direction of more efficacious, safer and less invasive methods.

\section{Closing Remarks}

The Annual Congress of the European Society of Cardiology (ESC) was successfully held in Munich from the $26^{\text {th }}$ to $29^{\text {th }}$ August 2012, and I would personally like to show my appreciation of the more than 1,200 abstracts submitted by Japanese cardiologists to this meeting. Since the ESC has recently realized that Japan has a highly sophisticated cardiology society with great research, it would like to collaborate with the JCS. I hope my report will generate interest among many young Japanese cardiologists to submit abstracts (deadline; St. Valentine's day, 14 ${ }^{\text {th }}$ February 2013) and attend the next ESC Congress to be held in Amsterdam from $31^{\text {st }}$ August to $4^{\text {th }}$ September 2013.

\section{References}

1. Nagai R, Pritzl N, Low RB, Stirewalt WS, Zak R, Alpert NR, et al. Myosin isozyme synthesis and mRNA levels in pressure-overloaded rabbit hearts. Circ Res 1987; 60: 692-699. 
2. Watanabe N, Kurabayashi M, Shimomura Y, Kawai-Kowase K, Hoshino Y, Manabe I, et al. BTEB2, a Krüppel-like transcription factor, regulates expression of the Memb/Nonmuscle myosin heavy chain B (SMemb/NMHC-B) gene. Circ Res 1999; 85: 182-191.

3. ESC 365 on the ESC web. http://www.escardio.org/congresses/ esc-2012/Pages/welcome.aspx (accessed 23 September, 2012)

4. Morice MC, Serruys PW, Sousa JE, Fajadet J, Hayashi EB, Perin M, et al. A randomized comparison of a sirolimus-eluting stent with a standard stent for coronary revascularization. N Engl J Med 2002; 346: $1773-1780$.

5. Grüntzig AR, Senning A, Siegenthaler WE. Nonoperative dilatation of coronary artery stenosis: Percutaneous transluminal coronary angioplasty. N Engl J Med 1979; 301: 61-68.

6. Ozaki Y, Keane D, Ruygrok P, van der Giessen WJ, de Feyter PJ, Serruys PW. Six-month clinical and angiographic outcome of the new less shortening Wallstent in native coronary arteries. Circulation 1996; 93: $2114-2120$.

7. Serruys PW, de Jaegere P, Kiemeneij F, Macaya C, Rutsch W, Heyndrickx G, et al; on behalf of the Benestent Study Group. A comparison of balloon-expandable-stent implantation with balloon angioplasty in patients with coronary artery disease. N Engl J Med 1994; 331: 489-495.

8. Ormiston JA, Serruys PW, Regar E, Dudek D, Thuesen L, Webster $\mathrm{MW}$, et al. A bioabsorbable everolimus-eluting coronary stent system for patients with single de-novo coronary artery lesions (ABSORB): A prospective open-label trial. Lancet 2008; 371: 899-907.

9. Brugada P, Brugada J. Right bundle branch block, persistent ST segment elevation and sudden cardiac death: A distinct clinical and electrocardiographic syndrome: A multicenter report. J Am Coll Cardiol 1992; 20: $1391-1396$.

10. Roe MT, Armstrong PW, Fox KA, White HD, Prabhakaran D, Goodman SG, et al; for the TRILOGY ACS Investigators. Prasugrel versus clopidogrel for acute coronary syndromes without revascularization. N Engl J Med 2012 August 25 [Epub ahead of print].

11. Camm AJ, Lip GY, De Caterina R, Savelieva I, Atar D, Hohnloser
SH, et al. 2012 focused update of the ESC Guidelines for the management of atrial fibrillation: An update of the 2010 ESC Guidelines for the management of atrial fibrillation * developed with the special contribution of the European Heart Rhythm Association. Eur Heart $J 2012$ August 24 [Epub ahead of print].

12. Aoki T, Fukumoto Y, Yasuda S, Sakata Y, Ito K, Takahashi J, et al. The Great East Japan Earthquake Disaster and cardiovascular diseases. Eur Heart J 2012 August 28 [Epub ahead of print].

13. Masumoto A, Mohri M, Shimokawa H, Urakami L, Usui M, Takeshita A. Suppression of coronary artery spasm by the Rho-kinase inhibitor fasudil in patients with vasospastic angina. Circulation 2002; 105: $1545-1547$.

14. Puymirat E, Simon T, Steg PG, Schiele F, Guéret P, Blanchard D, et $\mathrm{al}$; for the USIK USIC 2000 and FAST MI Investigators. Association of changes in clinical characteristics and management with improvement in survival among patients with ST-elevation myocardial infarction. JAMA 2012; 308: 998-1006.

15. Steg PG, James SK, Atar D, Badano LP, Lundqvist CB, Borger MA, et al. ESC Guidelines for the management of acute myocardial infarction in patients presenting with ST-segment elevation: The Task Force on the management of ST-segment elevation acute myocardial infarction of the European Society of Cardiology (ESC). Eur Heart J 2012 September 11 [Epub ahead of print].

16. Ozaki Y, Okumura M, Ismail TF, Motoyama S, Naruse H, Hattori K, et al. Coronary computed tomographic angiography characteristics of culprit lesions in acute coronary syndromes not related to plaque rupture as defined by optical coherence tomography and angioscopy. Eur Heart J 2011; 32: 2814-2823.

17. Bruyne BD, Pijls NHJ, Kalesan B, Barbato E, Tonino PAL, Piroth Z, et al, for the FAME 2 Trial Investigators. Fractional flow reserveguided PCI versus medical therapy in stable coronary disease. $N$ Engl J Med 2012; 367: 991 -1001.

18. Ikari Y, Ochiai M, Hangaishi M, Ohno M, Taguchi J, Hara K, et al. Novel guide catheter for left coronary intervention via a right upper limb approach. Cathet Cardiovasc Diagn 1998; 44: 244-247. 